\title{
“Colorir para agir": educar pela arte, para a paz
}

\author{
"Coloring for action": educate through art, for peace
}

\author{
Catarina Santos, Ana Paula Cardoso, Ana Luísa Marcelino \\ Instituto Politécnico de Viseu, CI\&DETS, Escola Superior de Educação
}

\begin{abstract}
Resumo
O projeto "Colorir para agir" foi concebido e implementado com o objetivo de alertar para a problemática crescente da violência escolar e contribuir para a prevenção e diminuição das práticas agressivas de crianças em idade escolar, procurando valorizar a convivência harmoniosa entre pares. Aliando a educação não formal às artes, este programa de intervenção desenvolveu um conjunto de atividades no âmbito das artes plásticas, abrangendo 21 crianças, com idades compreendidas entre os 6 e os 13 anos de um Agrupamento de Escolas de Valongo do Vouga, no concelho de Águeda (Portugal). Estas culminaram na realização de um mural gigante pintado na parede exterior da instituição, que ficou como símbolo da não violência escolar e da educação para a paz.

Palavras-chave: artes plásticas, crianças em idade escolar, educação não formal, violência escolar, paz.
\end{abstract}

\begin{abstract}
The project "Coloring for action" was designed and implemented in order to develop to draw attention to the growing problem of school violence and contribute to the prevention and reduction of aggressive practices of school children, looking to value the harmonious coexistence among peers. Combining non-formal education with the arts, this intervention developed a set of activities in the context of plastic arts, covering 21 children aged 6 to 13 years from Valongo of Vouga School Grouping in the municipality of Águeda (Portugal). These culminated with the creation of a giant mural painted on the outside wall of the institution, as a symbol of non-violence in schools and education for peace.

Keywords: plastic arts, school-age children, non-formal education, school violence, peace.
\end{abstract}

“Colorir para agir” é um projeto que tem como finalidade abordar duas temáticas importantes em contexto escolar: a violência na escola, enquanto questão a ser enfrentada, e a educação para a paz como meio de reflexão e prevenção.

São diversas as investigações que demonstram que a violência escolar (quer seja sistemática ou ocasional) é um fenómeno de caráter multifatorial, com diferentes expressões e variadas causas, sendo a escola um espaço privilegiado para a sua prevenção (Amado, 2001).

Perante este cenário, é importante desenvolver, em meio escolar, atividades que tenham em conta os interesses, os gostos e as necessidades das crianças, de forma a possibilitar uma melhor compreensão das razões que estão subjacentes à violência. Para além disso, revela-se fundamental educar os alunos, promovendo o sentido de responsabilidade, de respeito e de confiança entre pares. É, portanto, necessário apostar numa pedagogia da paz e procurar melhorar a convivência entre os participantes, permitindo que todas as partes envolvidas se sintam representadas e ouvidas no ambiente em que convivem (Abramovay \& Rua, 2002).

Os estudos sobre a paz têm início em meados do século $\mathrm{XX}$, construídos a partir de bases filosóficas que continuam a contribuir para fundamentar as reflexões e ações que se inserem nas temáticas ligadas à educação para a paz. Ao reconhecer a instituição Escola como um campo favorável ao desenvolvimento de valores éticos, importa questionar as interações estabelecidas em ambiente escolar. Tencionamos abrir um espaço de diálogo voltado para a prevenção da violência, partindo da perceção que as crianças têm sobre estas questões.

O conceito de violência escolar e educação para a paz serão o ponto de partida para a realização de um conjunto de atividades artísticas, de carater lúdico, que têm como objetivo a intervenção social.

Este projeto pretende ser um contributo para que a problemática da violência escolar, tão presente nos dias de hoje, seja tida em maior consideração pela sociedade. O seu propósito é o de alertar não só as crianças para este problema, mas também toda a comunidade envolvente. Isto justifica a ideia de juntar a intervenção à arte, como recurso educativo, ao mesmo tempo que pretende ser um contributo para a abordagem pedagógica do tema.

Este projeto utilizou as artes plásticas como recurso educativo, no âmbito da educação não formal. Assim, procurou-se verificar se os alunos participantes estão realmente cientes deste problema que os afeta diretamente e intervir, de uma forma diferente e divertida, a fim de desenvolver neles uma maior consciência do problema e a sua capacidade de reação positiva em caso de violência escolar.

\section{Da violência à inclusão escolar}

Atualmente, a violência escolar é motivo de grande preocupação. Vários autores têm tentado explicar as causas do fenómeno da violência. Segundo Miller e Kraus (2008), esta inclui diversos tipos de comportamento que surgem quando existe agressão, influência física ou psicológica, ameaça contra outra pessoa ou grupo; ela tem como objetivo principal ferir ou magoar tanto física como psicologicamente, com o uso 
de manipulação em geral, visando a demonstração de domínio e poder.

Matos (2008) refere a existência de três tipos de comportamentos de agressão: a verbal, que utiliza palavras ou expressões verbais (e.g., ameaça, insulto, críticas); a física, que é exercida através de ataque físico (e.g., bater, pontapear, empurrar, morder); e a social, que usa a exclusão social nas brincadeiras/atividades, propositadamente, ou o lançamento de boatos, que podem prejudicar o indivíduo visado.

Este fenómeno deteta-se em camadas etárias cada vez mais jovens, nomeadamente, ao nível da escolaridade básica. A ocorrência da violência escolar em idades tão precoces justifica a importância de variados estudos realizados nesta área, com vista à compreensão deste fenómeno e consequente implementação de medidas de caráter preventivo, que não devem ser perspetivadas de forma individual, mas institucional (Sousa, 2003).

Em Portugal, têm sido levados a cabo vários os estudos sobre a violência nas escolas. Fonseca (1992), com propósito de investigar a incidência dos comportamentos anti-sociais no ensino básico e secundário, realizou um estudo em Coimbra, com alunos com idades compreendidas entre os 8 e os 17 anos. Verificou-se que, desde cedo, um grande número de crianças se envolve em numerosas condutas anti-sociais e que a incidência destas leva a crer que não são exclusivas de uma classe socialmente desfavorecida.

Outro estudo efetuado por Lourenço, Pereira, Paiva e Gebara (2009), no norte de Portugal, teve como objetivo diagnosticar as práticas agressivas na escola. Nele constatou-se que "a maior parte das agressões ocorre no recreio” (p. 209). É por este motivo que os espaços livres são alvo da atenção de vários investigadores, pois é aqui que se desenvolvem atividades de interação das crianças com os seus pares que visam o desenvolvimento motor e a socialização.

Por conseguinte, é necessário procurar as causas que levam as crianças a atos de violência entre pares e, seguidamente, refletir sobre se os agressores não serão também vítimas do contexto onde se inserem ou tentam inserir-se, e se os mesmos se autoexcluem ou são excluídos pelos próprios ou por outros atores escolares (Pereira, 2008).

Para reduzir as práticas agressivas em contexto escolar é fundamental estabelecer uma estratégia de prevenção. Partilhando a perspetiva de Serrate (2009), mais do que conhecer e estudar as causas da violência escolar é necessário atuar no sentido da prevenção e pacificação. Diante da crise de identidade e de valor da instituição escolar, pretendeu-se verificar a importância da prática artística - num espaço de educação não formal - como mediadora do processo de inclusão social de crianças em situações de risco.

\section{A importância de educar para a paz}

A paz está intrinsecamente associada aos processos de transformação social; só através dela é possível superar a violência e promover a igualdade e o respeito. Ao falarmos em paz, temos de falar, obrigatoriamente, em educação para a paz.
Segundo Delors et al. (1997) a educação para o século XXI deve organizar-se em quatro saberes fundamentais, que serão, para cada indivíduo, os pilares do conhecimento: "o aprender a conhecer, isto é adquirir instrumentos de compreensão; aprender a fazer, para poder agir sobre o meio envolvente; aprender a viver juntos, a fim de participar e cooperar com os outros em todas as atividades humanas; finalmente aprender a ser, via essencial que integra as três precedentes” (p. 77).

Interessa aqui destacar a importância de aprender $a$ viver juntos, sendo que esta aprendizagem apresenta, nos dias de hoje, um desafio maior para a educação. A existência de conflitos em meio escolar é frequente, é um encontro de diferenças e deve ser encarado como um fator de crescimento pessoal e grupal, quando resolvido sem violência.

Diversos autores referem a necessidade de incentivar uma cultura de paz nas escolas (Guimarães, 2004; Jares, 2002; Milani, 2003; UNESCO, 1999; Valenzuela, 2009), entendendo a paz como um conceito dinâmico que contribui para provocar, enfrentar e resolver conflitos de uma forma não violenta. Segundo Guimarães (2004), deve-se pensar uma educação para a paz que reconheça o conflito como "um trampolim do desenvolvimento, que não postule a eliminação do conflito e que busque modos criativos e menos violentos de resolvê-los” (p.198).

Tanto a violência como a paz devem ser entendidas no contexto sociocultural. Nas palavras de Milani (2003), a "cultura de paz constitui-se dos valores, atitudes e comportamentos que refletem o respeito à vida, à pessoa humana e à sua dignidade, aos direitos humanos, entendidos em seu conjunto, interdependentes e indissociáveis". E assim considera que se deve "repudiar todas as formas de violência, especialmente a quotidiana e promover os princípios da liberdade, justiça, solidariedade e tolerância, bem como estimular a compreensão entre os povos e as pessoas” (p. 36).

Em suma, podemos afirmar que educar para a paz visa proporcionar uma mudança no comportamento social. A educação para a paz é o processo pedagógico que contribui, justamente, para a difusão, reflexão e desenvolvimento de uma cultura de paz. Ao aprender a viver juntos, também aprendemos a tolerar, a respeitar, a aceitar e, acima de tudo, a conviver de forma harmoniosa.

Por conseguinte, é necessário refletir sobre a necessidade de desenvolver valores como a justiça, a cooperação, a solidariedade, facilitando experiências e vivências da paz no contexto escolar, apoiando a resolução não violenta dos conflitos e fomentando a livre expressão do pensamento crítico, reconhecendo que o diálogo e o perdão são fundamentais para a tolerância que conduz à não violência e à paz.

Como podemos deduzir, é urgente encarar e procurar resolver estas questões nas escolas. E porque não fazer da arte uma forma de intervenção, criativa, diferente e divertida?

\section{Artes plásticas na educação das crianças e jovens}

São várias as perspetivas sobre o reconhecimento do valor educativo da arte. Dos estudos realizados constata-se uma discussão intensa sobre a validade das 
Artes Plásticas/Expressão Plástica como área do saber, ou como meio para a construção de conhecimento noutros domínios. Por outro lado, discute-se também a falta de reconhecimento pela sociedade e pela própria comunidade educativa do valor educativo da arte, o que pode verificar-se pela (falta de) relevância que lhe é atribuída na construção e desenvolvimento do currículo, numa grande parte das instituições educativas (Lameira, Cardoso \& Pereira, 2012).

É fundamental envolver desde cedo as crianças com as diversas linguagens artísticas, favorecendo assim a sua compreensão e familiarização num processo natural e integrado com outras aprendizagens desenvolvidas através da vivência de situações concretas do quotidiano (Gardner, 2001; Davis \& Gardner, 2002).

A primeira forma de arte a entrar no ensino foi o desenho, considerado um instrumento de cultura geral, estética e um meio de expressão de sentimentos. Passa então a ser dada importância à observação e o ensino desta área começa a desenvolver-se a partir de atividades espontâneas, tornando-se mais importante o desenvolvimento e implementação das artes plásticas.

Em a “Educação Pela Arte”, Read (2001) defende que as artes plásticas devem ser a base geral da educação como um desafio da ação educativa, considerando que a arte é um discurso universal e uma forma de comunicação. Para o mesmo autor "a comunicação implica a intenção de influenciar outras pessoas, sendo assim uma actividade social” (p. 82).

A tomada de consciência sobre a importância do ensino das artes está bem patente na Lei de Bases do Sistema Educativo (LBSE) de 14 de Outubro de 1986 (Pires, 1987). No seu artigo $7^{\circ}$, são focados alguns objetivos que visam a importante implementação das artes plásticas: c) Valorizar as atividades manuais e promover a educação artística, de modo a sensibilizar para as diferentes formas de expressão estética; f) Fomentar o gosto por uma constante atualização de conhecimentos; o) Criar condições de promoção do sucesso escolar e educativo a todos os alunos”.

A mesma Lei, no seu artigo $48^{\circ}$, aborda, entre outros aspetos, a ocupação dos tempos livres, referindo que:

1. As atividades curriculares dos diferentes níveis de ensino devem ser complementadas por ações orientadas para a formação integral e a realização pessoal dos educandos no sentido da utilização criativa e formativa dos seus tempos livres.

2. Estas atividades de complemento curricular visam, nomeadamente, o enriquecimento cultural e cívico, (...), a educação artística e a inserção dos educandos na comunidade.

Em conclusão, pode-se afirmar que a arte como forma de apreender o Mundo permite desenvolver o pensamento crítico e criativo e a sensibilidade; explorar e desenvolver novos valores; entender as diferenças culturais e constituir-se como expressão de cada cultura. A relevância das artes no sistema educativo centra-se no desenvolvimento de diversas dimensões do sujeito através da fruição/contemplação, produção e reflexão/interpretação.

Esta abordagem relativamente às artes plásticas cria condições para possibilitar às crianças realizar atividades artísticas na escola e, também, possibilita educar através da arte. Assim, esta permite desenvolver capacidades criativas, no sentido de promover novos saberes e fazeres que podem trazer à realidade uma imagem em projeto de um futuro mais humano e solidário.

\section{Projeto Artístico “Colorir Para Agir”}

\section{Problema e objetivos}

O projeto “Colorir para agir” tem subjacente a seguinte questão: Será que através da educação pela arte é possível consciencializar as crianças para a violência escolar e contribuir para a educação para a paz?

Como tentativa de resposta, o projeto procurou concretizar um plano de ação na área artística e com uma vertente interventiva social sobre a problemática da violência escolar. $O$ seu principal objetivo foi o de trabalhar com alunos do Agrupamento de Escolas de Valongo do Vouga, agrupamento identificado no âmbito dos Programas de Territórios Educativos de Intervenção Prioritária (TEIP) e realizar atividades, sobretudo ao nível das artes plásticas, tendo sempre presente o propósito de alertar e consciencializar para a não violência e promover a paz.

Numa situação de prioridade de intervenção educativa, como é o caso de um Agrupamento TEIP, a importância de criar um ambiente de responsabilização e de motivação é fundamental, assim como construir novas respostas que ajudem à minimização dos problemas identificados. O grande propósito da sua criação é o de melhorar o ambiente escolar, promovendo a igualdade de oportunidades educativas.

Este projeto teve ainda como objetivos específicos: conhecer a realidade escolar das crianças e desenvolver com elas atividades diversificadas e significativas, relativamente à problemática identificada; promover iniciativas educativas com o intuito de resolver conflitos e situações de violência que se verifiquem; ajudar na construção de mecanismos de minimização da violência escolar contribuindo para a melhoria das relações e da convivência entre as crianças.

As temáticas abordadas surgem a partir da importância de problematizar e refletir sobre a violência escolar através de uma metodologia participativa (Soares, 2006). Esta visa, por sua vez, redefinir o sentido social do trabalho com as escolas, da educação e da importância de saber viver em comunidade e de saber relacionar-se com os outros.

\section{Participantes}

O projeto foi desenvolvido com crianças em idade escolar que frequentam o $1 .^{\circ}$ e $2 .^{\circ}$ Ciclos do Ensino Básico no Agrupamento de Escolas de Valongo do Vouga, um agrupamento TEIP.

A escolha recaiu nas crianças do Centro de Atividades Livres da Casa do Povo de Valongo do Vouga, uma resposta social da junta de freguesia criada para acolher crianças do referido Agrupamento. A opção por esta instituição e valência justifica-se pelo facto de ser o local em que a investigadora exerce a sua atividade profissional enquanto animadora cultural. 
No total, o projeto foi desenvolvido com 21 participantes tendo para o efeito sido constituídos dois grupos. O primeiro integrou dez crianças, sete raparigas e três rapazes, com idades compreendidas entre os 6 e os 8 anos de idade. Todos eles frequentavam as Escolas EB 1 de Arrancada e de Valongo do Vouga, sendo que duas crianças frequentavam o $1^{\circ}$ ano de escolaridade, duas o $2^{\circ}$ ano, uma frequentava o $3^{\circ}$ ano e cinco estavam a frequentar o $4^{\circ}$ ano.

O segundo grupo de participantes contou com um total de onze crianças, sete rapazes e quatro raparigas, dos 9 aos 13 anos, sendo todos alunos da Escola EB 2/3 de Valongo do Vouga. Destes participantes seis frequentavam o $5^{\circ}$ de escolaridade e quatro o $6^{\circ}$ ano.

De salientar que os participantes residem todos nas imediações de Valongo do Vouga, sendo a maioria oriunda de famílias com nível de escolaridade relativamente baixo, correspondente ao $1^{\circ}$ e $2^{\circ}$ Ciclos do Ensino Básico. Verificam-se casos de carências socioeconómicas resultantes da crise no setor industrial circundante, sendo que uma parte significativa dos alunos (29,8\%) beneficia de auxílios económicos.

\section{Diagnóstico da necessidade de intervenção}

O diagnóstico da necessidade de intervenção foi realizado através de um questionário presencial. A análise dos dados extraídos permitiu-nos reunir informações essenciais para a elaboração de um programa de intervenção que procurou ir ao encontro dos interesses e motivações dos participantes.

A maioria das crianças $(52,4 \%)$ referiu que a escola é um lugar pouco seguro, constatando-se que é durante o intervalo, no recreio, que acontecem os episódios de maior violência. Como explicam na resposta aberta, os “empurrões”, o “chamar nomes” e as “asneiras” são uma constante durante o recreio e as disputas que acabam em "porrada” são bastantes frequentes.

No que respeita a atos de violência física exercidos dentro do espaço escolar, todos os alunos afirmam que já assistiram a situações de violência dentro do espaço escolar, seja ela de caráter físico ou psicológico. A percentagem de crianças que já foram algumas vezes vítimas é igual à percentagem de alunos que responderam que nunca o foram (36,85\%). Porém, é de extrema importância ressaltar que mais de um quarto das crianças (26,31\%) afirma que já foi vítima de violência física muitas vezes. A agressão psicológica é também uma constante: nove crianças $(47,36 \%)$ referiram que já foram vítimas deste tipo de agressão, contra sete $(36,85 \%)$ que declararam que nunca o foram.

Verificou-se também que grande parte das crianças (84,20\%) está consciente de que é necessário intervir para mudar esta situação. Tendo sido apresentadas várias possíveis atividades a realizar como forma de intervenção, apenas uma pequena parte dos alunos assinalou a realização de palestras/seminários (15,8\%), ou a criação de um hino $(10,52 \%)$, sendo que a grande maioria $(63,16 \%)$ referiu que seria interessante realizar um mural gigante numa parede da escola - o que veio a constituir um indicador de preferência que tomámos em consideração no planeamento das atividades do projeto.

\section{Descrição e análise das atividades desenvolvidas}

O projeto de intervenção privilegiou as atividades ligadas às artes plásticas, nomeadamente o desenho e a pintura e foi construído com o contributo de todos os intervenientes e objeto de reflexão permanente. O plano de atividades foi desenvolvido em três fases distintas com ações e objetivos inerentes a cada uma delas, num total de 13 sessões de trabalho que decorreram de Janeiro a Maio de 2014.

Numa primeira fase foram realizadas sessões programadas de atividades com o intuito de conversar em grupo e de levar os participantes a refletir sobre a violência escolar, a sua origem e como intervir de forma a prevenir situações deste tipo. Estas conversas serviram para cativar as crianças, e deixá-las confortáveis para falar num assunto tão delicado.

De seguida, foram realizadas atividades práticas como a visualização de uma animação infantil sobre o tema, “A aranha Popô rompendo a corrente”, onde era mostrada a importância de quebrar o ciclo vicioso de violência e agir de modo a viver em harmonia com o outro. A observação de imagens relacionadas com violência escolar, por um lado, e com educação para a paz, por outro, foram um importante instrumento de reflexão. Ao observá-las as crianças puderam percecionar a gravidade da violência escolar e compreender como é importante atuar no sentido da educação para a paz.

Por fim, foi pedido que fizessem desenhos sobre a sua escola tal e qual como a veem e sentem e também como gostariam que a mesma fosse. Destes desenhos foram analisados e retirados os elementos figurativos que serviram para a composição visual do mural.

Através da análise dos desenhos foi possível perceber que algumas crianças optaram por ilustrar situações que já haviam sido descritas verbalmente. É importante referir que algumas das crianças fizeram questão de legendar os seus desenhos ou de ressaltar as expressões faciais de tristeza das figuras para que não houvesse dúvidas relativamente à situação de violência escolar presente. No caso dos desenhos alusivos à paz, as crianças desenharam elementos harmoniosos que nos remetem para a alegria, paz, harmonia, felicidade, valores que as crianças desejam que estejam sempre presentes. Foram utilizadas cores vivas, como o azul, o verde, o amarelo, o roxo e o laranja.

A segunda fase do projeto consistiu na realização da pintura no mural. Esta teve como objetivo primordial dar a oportunidade às crianças de serem protagonistas no processo de fortalecimento da paz e, ao mesmo tempo, criar um elemento representativo da não violência que ficasse gravado no espaço escolar depois da conclusão do projeto.

Foram organizados os elementos figurativos, tendo em atenção os desenhos realizados anteriormente, para a composição visual do mural e procedeu-se ao início do esboço. Dos elementos escolhidos para compor o mural importa referir a escolha dos meninos de mãos dadas, a que podemos associar a importância do outro para o desenvolvimento social. Outro elemento fundamental na escolha dos elementos figurativos para o mural foi o desenho de uma escola. Aqui foi fundamental, para as 
crianças, escrever os valores que consideram que devem ser praticados (cf. Figura 1).

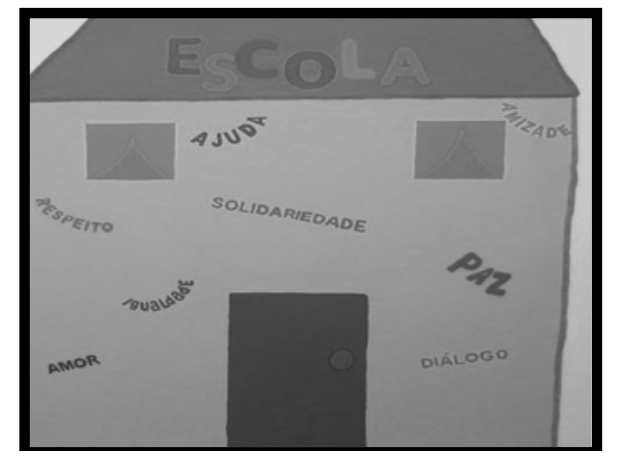

Figura 1. Imagem da escola realizada pelos alunos

Os valores escolhidos pelos participantes para serem representados mostram que as crianças já começam a estar sensibilizadas para a importância da cidadania. Contudo, é necessário desenvolver ações que desenvolvam o respeito mútuo entre os membros da comunidade escolar, a justiça, a solidariedade, a amizade e outros valores importantes para a construção de uma sociedade mais justa e fraterna.

Pintar o mural foi a atividade que mais despertou o interesse e o empenho das crianças. De salientar a reação extremamente positiva das crianças e das pessoas ligadas à instituição, encarregados de educação e familiares. Além disso, Todas as crianças queriam participar nas "pinturas" e, ao fazê-lo, a primeira reação era chamar os seus familiares para verem o "bocadinho" que tinha sido pintado por eles. Foram muitos os comentários que referiam que o mural tinha sido muito bem conseguido, que o espaço tinha ganho muito com a sua realização, tinha ficado mais acolhedor, mais alegre e mais simpático (cf. Figura 2).

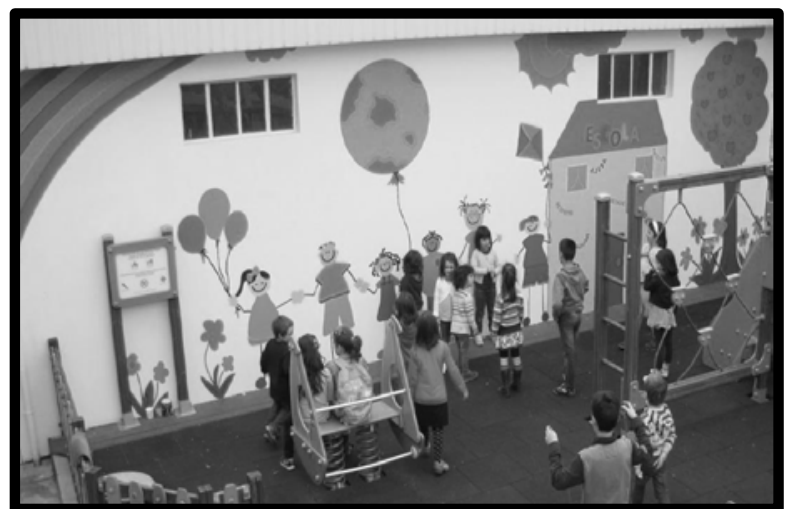

Figura 2. Mural da não violência escolar

Concluído o mural houve necessidade de realizar uma atividade de encerramento do projeto. Esta terceira fase teve como objetivo consolidar os vários contributos provenientes de todo o processo e de evidenciar a ideia de que lutar contra a violência escolar depende de todos e que só assim se pode tentar diminuir este flagelo.

A atividade "Todos juntos construímos o caminho" desenrolou-se em duas etapas distintas. Na primeira, os participantes tinham de escrever/desenhar um episódio negativo de que tivessem sido alvo ou que tivessem assistido na escola. Feito isto, era proposto à criança que amachucasse o papel com força e depois o tentasse alisar o melhor que conseguisse.

Esta tarefa foi realizada para que os participantes percebessem que depois de viver um episódio de violência dificilmente seremos os mesmos. Aqui era explicado que ao passar-se por uma experiência traumática ficamos com marcas e cicatrizes muito profundas e difíceis de ultrapassar. De seguida, a "recordação" era pendurada na árvore para que ficasse exposta e se pudesse ter contacto com relatos de violência escolar das crianças.

A segunda etapa da atividade consistia em fazer o contrário da primeira, ou seja, percorrer o caminho para a paz. Aqui os participantes dispunham de pedras coloridas, onde era pedido para escrever um valor que fosse útil nesta caminhada a favor da paz. Assim, pedra a pedra e de valor em valor todos juntos construímos o caminho a favor da não violência e rumo à paz.

\section{Avaliação final do projeto}

As respostas ao questionário de avaliação final permitiram constatar que a grande maioria das crianças (77,28\%) gostou "muito" de participar neste projeto e que gostariam de, no futuro, participar em projetos semelhantes. A par de tudo isto foi ainda possível constatar o entusiasmo e a avaliação positiva dos participantes, quando a quase totalidade $(90,90 \%)$ das crianças classificou como "bom" o grau de interesse pelo projeto.

Relativamente ao produto final desenvolvido, o mural, podemos concluir que foi do agrado da grande maioria dos participantes (86,36\%). Apenas 13,64\% dos alunos o classifica com um trabalho “razoável”. De salientar ainda que a quase totalidade dos participantes (90,90\%) respondeu que as atividades realizadas permitiram sensibilizá-los para o problema da violência escolar e só dois $(9,10 \%)$ revelou a opinião contrária.

Em síntese, podemos concluir que, de um modo geral, as crianças gostaram de participar neste projeto, umas mais do que outras, o que pode dever-se às atividades serem direcionadas para a expressão plástica e esta pode não constituir a preferência de todos os participantes. Consideramos também que os projetos que envolvem atividades práticas têm mais impacto junto das crianças, principalmente se foram áreas artísticas com que estas se identifiquem. As artes plásticas podem ser uma importante metodologia de trabalho para projetos que têm em vista captar o interesse das crianças e chamá-las a atenção para problemáticas sociais que as afetam.

Por outro lado, tratando-se de atividades que ficam expostas para toda a comunidade, como é o caso do mural desenvolvido, a primeira reação das crianças é mostrar o trabalho que realizaram, chamando familiares e amigos ao espaço, tornando possível cativar outros participantes para trabalhos idênticos e ao mesmo tempo, alargar a influência do projeto à comunidade. 


\section{Conclusão}

O projeto "Colorir para agir" baseou-se essencialmente, em dois pilares, a educação e as artes. Para o seu desenvolvimento foi necessário articular estas áreas, bem como proceder ao diagnóstico e estudo do ambiente escolar vivido pelos participantes, a fim de adequar a intervenção ao público-alvo.

Para transformar a realidade atualmente vivida nas escolas e tornar este espaço um ambiente mais agradável, alegre e acolhedor, onde o processo de aprendizagem ocorra de forma equilibrada e igualitária, é necessário repensar as práticas e os recursos utilizados, de forma a valorizar as experiências, desejos e necessidades dos alunos.

Este projeto procurou desenvolver atividades lúdicas dentro das artes plásticas, como forma de intervenção e, consequentemente, levar à mudança de atitudes. Foi nosso propósito criar um ambiente descontraído, onde os participantes se sentissem à vontade para falar de problemas relacionados com a violência escolar e, assim, proporcionar momentos de reflexão, levando as crianças a entender a necessidade da harmoniosa relação com o outro e desta forma favorecer a diminuição de situações de conflito entre pares.

Houve uma grande preocupação em ouvir as crianças, de forma a conhecer a realidade escolar por elas vivida e, assim, desenvolver atividades que fossem ao encontro dos seus interesses. Foram promovidas iniciativas com o intuito de ajudar a minimização da violência contribuindo, deste modo, para a melhoria da convivência entre pares. Foram também criadas oportunidades de os participantes serem protagonistas num processo de fortalecimento da paz, onde o diálogo e a reflexão foram assumidos como caminhos (estratégias) a seguir.

Assim, foi possível que as ocorrências de violência fossem alvo de atenção, de esclarecimento, de reflexão sobre a importância do pedido de desculpas e de arranjar estratégias de apaziguamento. Mais do que sensibilizar para o tema, foi possível, partindo das capacidades, interesses, necessidades, conhecimentos e dúvidas das crianças, consciencializar para a não violência e contribuir para a paz.

O diálogo e a reflexão são os caminhos que devem ser assumidos pela escola como espaço de aprendizagem e de transmissão de valores. É importante realçar que todos estes conhecimentos foram adquiridos através de uma vertente artística, no contexto da educação não formal.

Projetos como este apresentam a arte como uma linguagem universal e como promotora das relações interpessoais e culturais, contribuindo para a criação de cidadãos mais conscientes e solidários. Aspetos que nos remetem para a afetividade, para a comunicação e para a construção do "Eu” na relação com o outro.

Julgamos assim ter contribuído para a integração das práticas artísticas dentro do contexto educativo, despertando nas crianças o sentido crítico e a sensibilidade estética através da expressão artística, unindo a arte à educação.

\section{Referências}

Abramovay, M. \& Rua, M. G. (2002). Violência nas escolas. Brasília: Unesco.

Amado, J. (2001). Interacção pedagógica e indisciplina na aula. Porto: ASA.

Davis, J. \& Gardner, H. (2002). As artes e a educação de infância: Um retrato cognitivo-desenvolvimental da criança como artista. In B. Spodek (Org.) (2002), Manual de investigação em educação de infância (pp.427-460). Lisboa: Fundação Calouste Gulbenkian.

Delors, J. et al. (1997). Educação: Um tesouro a descobrir ( $3^{\mathrm{a}}$ ed.). Porto: ASA.

Fonseca, A. (1992). Comportamentos anti-sociais no ensino básico. Revista Portuguesa de Pedagogia, 26, 279-300.

Gardner, H. (2001). A criança pré-escolar: Como pensa e como a escola pode ensiná-la ( $2^{\mathrm{a}}$ ed.). Porto Alegre: Artes Médicas.

Guimarães, M. R. (2004). Um novo mundo é possível: Dez razões para educar para a paz, praticar a tolerância, promover o diálogo inter-religioso, ser solidário, promover os direitos humanos. São Leopoldo: Sinodal.

Jares, X. R. (2002). Educação Territórios Educativos de Intervenção Prioritária: Para a paz sua teoria e sua prática ( $2^{\mathrm{a}}$ ed.). Porto Alegre: Artmed.

Lameira, R., Cardoso, A. P. \& Pereira, J. (2012). A perceção dos professores sobre o lugar e a presença da Expressão Plástica na escola do $1^{\circ}$ Ciclo do Ensino Básico. Revista Portuguesa de Pedagogia, 46 (2), 49-67.

Lourenço, L. M., Pereira, B. O., Paiva, D. P., Gebara, C. (2009). A gestão educacional e o bullying: Um estudo em escolas portuguesas. Interações, 13, 208-228.

Matos, M., Tomé, G., Gaspar, T., Camacho, I., Ferreira, M., Borges, A., \& Morais, M. (2008). Bullying/provocação nas escolas portuguesas: Da investigação à intervenção em meio escolar. O estudo OMS em Portugal. $4^{a}$ Conferência Mundial. Violência na escola e Políticas Públicas (pp.170-171). Lisboa: Faculdade de Motricidade Humana de Lisboa.

Milani, F. M. (2003). Cultura de Paz x Violências: Papel e desafios da escola. Cultura de Paz: Estratégias, mapas e bússolas. Salvador: INPAZ.

Miller, T. \& Kraus, R. (2008). School-related violence: Definition, scope and prevention goals. School violence and primary prevention (pp. 15-24). New York: Springer.

Pereira, B. O. (2008). Para uma escola sem violência. Estudo e prevenção das práticas agressivas entre crianças. Lisboa: Fundação Calouste Gulbenkian e Ministério da Ciência e Tecnologia (MCT).

Pires, E. (1987). Lei de Bases do Sistema Educativo: Apresentação e comentários. Porto: ASA.

Read, H. (2001). A educação pela arte. São Paulo: Martins Fontes.

Serrate, R. (2009). Lidar com o bullying na escola. Sintra: K Editora.

Soares, N. F. (2006). A investigação participativa no grupo social da infância. Currículo sem fronteiras, 6 (1), 25-40. 
UNESCO (1999). Manifesto 2000: Por uma cultura de paz e não violência. Paris: UNESCO.

Sousa, A. (2003). Educação pela arte e artes na educação. Lisboa. Instituto Piaget.

Valenzuela, A. P. (2009). Professor e a educação para a paz. Revista Portuguesa de Pedagogia, 43 (2), 141-155.

\section{Agradecimentos}

A realização deste projeto contou com o apoio da Fundação para a Ciência e Tecnologia (FCT), através do Centro de Estudos em Educação, Tecnologias e Saúde (CI\&DETS) do Instituto Politécnico de Viseu. 